\title{
RELATORIO DO ANNO 1923
}

Cumprindo o disposto da letra $i$ ) do art. 114 do decreto 11.530, de 18 de Março de 1915 e em o n." XVII do art. $9 .^{\circ}$ do Regimento Interno desta Faculdade, passo a fazer o relatorio minucioso de tudo quanto occorreu neste estabelecimento a respeito da ordem, disciplina, serviço militar, observancia das leis e do orçamento do anno lectivo de 1923.

Abertura dos trabalhos. - Na fórma do disposto no art. 74 do decreto 11.530 de 18 de Março de 1915 e do art. 143 do Regimento Interno desta Faculdade, os trabalhos deste instituto de ensino abriram-se no dia $1 .^{\circ}$ de Março, celebrando a Congregação dos professores, nesse mesmo dìa, a sua primeira reunião.

Presença dos professores. - Na primeira reunião da Congregação do anno lectivo findo, realisada a 1. ' de Março, foi verificado que se achavam promptos para o concurso os professores: Drs. Uladislau Herculano de Freitas, Antonio Amancio Pereira de Carvalho, Antonio Januario Pinto Ferraz, Manoel Pedro Villaboim, José Ulpiano Pinto de Souza, Candido Nazianzeno Nogueira da Motta, Gabriel José Rodrigues de Rezende, Reynaldo Porchat, Frederico Vergueiro Steidel, João Braz de Oliveira Arruda, Estevam de Araujo Almeida, Manoel Pacheco Prates, Luiz Barbosa da Gama Cerqueira, José Manoel de Azevedo Marques, Theophilo Benedicto de Souza Carvalho, José Joaquim Cardozo de Mello Neto, 
Francisco Antonio de Almeida Morato, o substituto em regencia de cadeira: Braz de Souza Arruda e os substitutos, que não regiam cadeiras: Spencer Vampré, Raphael Corrêa de Sampaio, José Augusto Cesar, Octavio Mendes e José de Alcantara Machado d'Oliveira.

Exame vestibular. - Na fórma do art. 62 do Regimento Interno, a inscripção para este exame instituido pelo art. 77, letra e) e do decrèto 11.530 de 1915, para a matricula no curso desta Faculdade, aberta a 2 de Janeiro e encerrada a 12 do mesmo mez, e, reaberta a 7 de Março, de conformidaidé com o dispósto no art. 2. ${ }^{\circ}$ do decreto n. ${ }^{\circ} 4228$, de 30 de Dezembro de 1920 e a resolução do Conselho Superior do Ensino, tomada em sessão realizada a 23 de fevereiro de 1821, foi encerrada a 15 do mesmo mez, tendo a ella concorrido sessenta e oito candidatos, sendo na primeira epoca vinte e dois (22), e na segunda, quarenta e seis (46). O exame iniciou-se com a prova escripta, para os inscriptos na: $1 .^{\text {" epoca, no dia } 27}$ de Janeiro, tendo terminado no dia 30 desse mesmo mez, e, para os inscriptos na 2. epoca, no dia 20 de Março e terminado no dia 24 desse mesmo mez. O resultado desse exame foi o seguinte: Em Janeiro, approvados 13, reprovados 3 e inhabilitados 5, não tendo comparecido á prova escripta 1, total 22; e, em Março, approvados 32, reprovados 7 e inhabilitados 7 , total 46. A commissão julgadora desse exame foi constituida, na primeira epoca, dos Drs. Frederico Vergueiro Steidel, Candido Nazianzene Nogueira da. Motta, em substituição ao Dr. Estevam de Araujo Almeida, Theophilo Benedicto de Souza Carvalho, Francisco Antonio de Almeida Morato, José : Augusto Cesar e Spencer Vampré, e na 2. ${ }^{a}$ epoca, dos Drs. Frederico Vergueiro Steidel. Theophilo Benedicto de Souza Carvalho, Francisco Antonio de Almeida Morato, Jọsé Augusto Cesar, Spencer Vampré e Manoel Pacheco Prates, em substituição ao Dr. Estevam de Araujo Almeida. 
Horario das aulas...- Pela Congregação dos professores, em sessão de $1 .^{\circ}$ de Março, foi adoptado o horario das aulas, constante do annexo respectivo.

Programmas de ensino. - Adoptados pelos Professores das cadeiras do curso, foi nomeada uma commissão composta dos Drs. José Joaquim Cardoso de Mello Neto, Theophilo Benedicto de Souza Carvalho e Francisso Antonio de Almeida Morato, a qual formulou seu parecer, opinando pela sua approvação, parecer esse que foi approvado na mesma sessão de 1 . de Março. Os programmas foram impressos e postos á venda na Thesouraria da Faculdade.

Designação de Professores. - No correr do anno findo, foram designados: Dr. Frederico Vergueiro Steidel, Professor cathedratico, para preencher o logar de substituto da 6." secção, vago pela nomeação do Dr. Octavio Mendes para cathedratico de Direito Commercial; Dr. Theophilo Benedicto de Souza Carvalho, Professor cathedratico, para reger a $1 .^{a}$ cadeira do $2 .^{\circ}$ anno, em substituição ao Dr. Braz de Sousa Arruda; Dr. Spencer Vampré, Professor substituto da $1 .{ }^{a}$ seç̧ão, para reger a $4 .^{a}$ cadeira do $5:^{\circ}$ anno, em substituição ao Dr. Manoel Pedro Villaboim e a $3 .^{a}$ cadeira do $1 .^{\circ}$ anno, em substituição ao Dr. Reynaldo Porchat, e para fazer o curso complementar de Direito Romano; Dr. Braz de Sousa Arruda, Professor substituto da 2. ${ }^{a}$ secção, para reger a $2 .^{a}$ cadeira do $1 .{ }^{\circ}$ anno, em substituição ao Dr. Uladislau Herculano de Freitas; Dr. José Augusto Cesar, Professor substituto da 3. " secção, para reger a 3. ${ }^{a}$ cadeira do $3 .^{\circ}$ anno, em substituição ao Dr. José Ulpiano Pinto de Souza; Dr. Raphael Corrêa de Sampaio, Professor substituto da 4." secção, para reger a 2." cadeira do $5 .^{\circ}$ anno; em substituição ao Dr. José Manoel de Azevedo Màrques; e Dr. Octavio Mendes, então Professor substituto da $6 .^{. "}$ secção, para reger a $1 .^{a}$ 
cadeira do $3 .^{\circ}$ anno, vaga com o fallecimento do Professor cathedratico Dr. Gabriel José Rodrigues de Rezende.

Exames de curso, na segunda epoca. - Para os exames da $2 .^{\mathrm{a}}$ epoca, inscreveram-se 73 alumnos, sendo no $1 .^{\circ}$ anno 22 , no 2 . 10 , no $3 .^{\circ} 12$, no $4 .^{\circ} 21$, e no $5 .^{\circ} 6$. 0 resultado desses exames, consta do Annexo respectivo.

Inscripção de matricula. - Matricularam-se nos cinco annos do curso 348 alumnos, sendo: no $1 .^{\circ}$ anno 62 , no $2 .^{\circ} 71$, no $3 .^{\circ} 56$, no $4 .^{\circ} 46$ e no $5 .^{\circ} 113$.

Transferencia de matricula. - Durante o periodo das ferias, dois alumnos pediram guiai de transferencia, sendo um do $1 .{ }^{\circ}$ anno, para a Faculdadei Livre de Direito do Estado de Minas Geraes e um do terceiro anno, para a Faculdade de Direito da Universidade do Rio de Janeiro.

Licenças. - Durante o anno lectivo findo, estiveram no goso de licença: o Dr. José Ulpiano Pinto de Souza, Professor cathedratico da $3 .^{\mathrm{a}}$ cadeira do $3 .^{\circ}$ anno, de 6 de Julho a 1." de Agosto; o Dr. Gabriel José Rodrigues de Rezende, Professor cathedratico da $1 .^{n}$ cadeira do $3 .^{\circ}$ anno, de 12 de Abril a 17 de Maio, vespera do dia 18, em que falleceu; o Dr. José Manoel de Azevedo Marques, Professor cathedratico da $2 .^{a}$ cadeira do $3 .^{\circ}$ anno, de $1 .^{\circ}$ Agosto a 16 de Dezembro; e o Dr. Braz de Sousa Arruda, Professor substituto da 2. ${ }^{a}$ secção, de 24 de Setembro a 10 de Outubro.

Fallecimento. - No dia 18 de Maio, falleceu o Dr. Gabriel Jøsé Rodrigues de Rezende, Professor cathedratico do Direito Commercial, com exercicio na $1 .^{\text {it }}$ cadeira do $3 .^{\circ}$ anno.

Vaga do logar do Professor aathedratico. - Com o fallecimento do' Dr. Gabriel José Rodrigues de Rezende, ficou vaga a 1." cadeira do: 3.' anno - Direito Commercial $\left(1 .^{\mathrm{a}}\right.$ parte $)$. 
Nomeação e posse de professor cathedratico. - Por decreto de 21 de Julho, do Presidente da Republica, foi nomeado o Dr. Octavio Mendes, Professor substituto da 6. ${ }^{\text {a }}$ secção, para o logar de Professor cathedratico de Direito Commercial ( $1 .^{\mathrm{a}}$ cadeira do $3 .^{\circ}$ anno), cadeira vaga com o fallecimento do Dr. Gabriel José Rodrigues de Rezende, tendo o nomeado tomado posse e entrado em exercjcio desse cargo, no dia 20 de Agosto.

Vaga de logar de Professor substituto. - Com a posse do Dr. Octavio Mendes no logar de Professor cathedratico da $1 .{ }^{\prime}$ cadeira do $3 .^{\circ}$ anno, ficou vago o logar de Professor substituto da $6 .^{a}$ secção.

Serviço Publico. - Durante o anno findo, estiveram ausentes desta Faculdade, por motivo de serviço publico: o Dr. Uladislau Herculano de Freitas, Director, como representante desta Faculdade no Conselho Superior do Ensino, de $1 .^{\circ}$ de Fevereiro a 11 de Março e de 16 de Julho a 7 de Agosto; o Dr. Reynaldo Porchat, como representante desta Faculdade, no Conselho Superior do Ensino, de $1 .^{\circ}$ de Fevereiro a 13 de Março e de 16 de Julho a 7 de Agosto; e o Dr. Manoel Pedro Villaboim, com assento no Congresso Nacional, como Deputado por este Estado de São Paulo, de 4 de Maio a 31 de Dezembro.

Substituições. - No correr do anno lectivo findo, o Dr. Antonio Amancio Pereira de Carvalho, Professor cathedratico mais antigo e vice-Director, na forma da lei, substituiu ao Dr. Uladislau Herculano de Freitas, no exercicio do cargo de Director, de l. de Fevereiro a 11 de Março e de 16 de Julho a 7 de Agosto; o Dr. Theophilo Benedicto de Souza Carvalho, Professor cathedratico, de 24 de Setembro a 10 de Outubro, substitutiu ao Dr Braz de Sousa Arruda, na regencia da $1 .^{\prime \prime}$ cadeira do 2. anno; o Dr. Spencer Vampré, substituto da l." secção, de 4 de Maio a 31 de Dezembro, substituiu ao Dr. Manoel Pedro 
Villaboim, na regencia da $4 .^{a}$ cadeira do $5 .^{\circ}$ anno, e, de ] 6 de Julho a 7 de Agosto, ao Dr. Reynaldo Porchat, na regencia da 3." cadeira do 1. ${ }^{\circ}$ anno; o Dr. Braz de Sousa Arruda, substituto da 2." secção, de 16 de Julho a 7 de Agosto, substituiu ao Dr. Uladislau Herculano de Freitas, na regencia da 2. ${ }^{a}$ cadeira do 1. anno; o Dr. José Augusto Cesar, substituto da 3 . secção, de 6 de Julho a $1 .^{\circ}$ de Agosto, substituiu ao Dr. José Ulpiano Pinto de Souza, na regencia da $3 .^{\mathrm{a}}$ cadeira do $3 .^{\circ}$ anno; o Dr. Raphael Corrêa de Sampaio, de 1. de Agosto a 16 de Dezembro, substituiu ao Dr. José Manoel de Azevedo Marques, na regencia da 2. ${ }^{\text {a }}$ cadeira do 5 . anno; e o Dr. Octavio Mendes, então Professor substituto da $6 .^{a}$ seç̧ão, de 12 de Abril a 19 de Agosto, substituiu ao Dr. Gabriel José Rodrigues de Rezende, na regencia da 1." cadeira do 3." anno.

Exames do curso, na primeira epoca. - Para estes exames inscreveram-se 306 alumnos, sendo no $1^{\circ}$ anno 52 , no $2 .^{\circ} 64$, no 3 . 44 , no $4 .^{\circ} 40$, e no $5 .^{\circ} 106$. O resultado desse exames, consta do Annexo respectivo.

Collação de grau. - Durante o anno lectivo findo, foi collado o grau de Bacharel em Sciencias Juridicas e Sociaes a cento e quinze (115) bacharelandos, dos quaes 1 concluiu o curso em 1922, 8 em Março de 1923 e cento e seis (106) o concluiram na primeira epoca do anno lec. tivo findo. Desses cento e quinze Bachareis, 89 são naturaes do Estado de São Paulo, 11 do Estado do de Minas Geraes, 3 do Estado de Rio de Janeiro, 2 da Cidade do Rio de Janeiro, 2 do de Sergipe, 2 do de Rio Grande do Norte, 2 do de Santa Catharina, 2 do de Rio Grande do Sul, 1 de Portugal, I da Italia. (Annexo respectivo).

Cartas de Bacharel. - Durante o anno findo, foram expedidas oitenta e quatro (84) Cartas a egual numero de Bachareis formados em Sciencias Juridicas e Sociaes 
por esta Faculdade. Desses 84 Bachareis, são naturaes do Estado de São Paulo 56, do de Minas Geraes 8, do de Rio de Janeiro 4, da Cidade do Rio de Janeiro, 2, do Estado de Santa Catharina 2, do de Sergipe 2, do da Parahyba 1, e da Italia 2. (Annexo respectivo).

Serviço Militar. - - De cunformidade com a informação prestada pelo respectivo Instructor, durante o anno findo, frequentaram a instrucção militar apenas dez (10) alumnos desta Faculdade, tendo prestado exame somente oito (8) os quaes foram approvados, tendo faltado as provas 2.

Interposição de recurso. - A 27 de Janeiro do anno findo, foi remettido ao Presidente do Conselho Superior do Ensino o recurso que o Professor cathedratico Dr. Frederico Vergueiro Steidel interpuzera para o referido Conselho Superior, da deliberação da Congregação dos Professores desta Faculdade, que, em sessão realizada a 16 de Novembro de 1922, mandara relevar as faltas dadas pelos alumnos do $3 .^{\circ}$ anno, durante os 15 primeiros dias do mez de Junho desse mesmo anno, recurso esse que teve o seu processo regular e, em sessão do mesmo Conselho Superior, realizada a 6 de Fevereiro do anno findo, foi considerado prejudicado por unanimidade de votos, conforme officio de communicação n. 6, de Março seguinte, do Presidente do mesmo Conselho, por não aproveitar ao caso concreto a deliberação que sobre o seu merito fosse tomada pelo mencionado Conselho Superior do Ensino.

Sessões da Congregação. - No decorrer do anno findo, a Congregação dos professores desta Faculdade celebrou sete (7) sessões, nas quaes foram tratados diversos assumptos.

Procedimento dos alumnos. - $\mathrm{O}$ procedimento dos alumnos, no correr do anno lectivo findo, foi bom, nada tendo occorrido digno de menção. 
Bibliotheca. - A bibliotheca desta Faculdade, como consta do annexo respectivo, foi frequentada, durante o anno findo, por 6.326 pessoas, que consultaram 2.702 obras em 5.606 volumes, sendo em portuguez 1.884 , em francez 576, em italiano 110 , em latim 78, em hespanhol 69 , e em inglez 21, estando no numero dos consulentes 2.078 pessoas que leram jornaes e revistas. deveres.

Os empregados da Bibliotheca bem cumpriram os seus

Thesouraria. - $\mathrm{O}$ balanço demonstrativo da Thesouraria desta Faculdade, constante do annexo respectivo, fechado a 31 de Dezembro findo, accusa que da Receita e. Despeza ha um saldo de 756:394\$400 (setecentos e cincoenta e seis contos trezentos e noventa e quatro mil e quatrocentos réis) assim distribuidos: no Banco do Commercio e Industria de São Paulo 10:514\$200 (dez contos quinhentos e quatorze mil duzentos réis), no Banco do Brasil $59: 880 \$ 200$ cincoenta e nove contos oitocentos e oitenta mil duzentos réis) e 686:000\$000 (seiscentos e oitenta e seis contos), valor de 686 ápolices da União, do valor de l:000\$000 (um conto de réis) cada uma, ao juro de cinco por cento $(5 \%)$ ao anno.

O saldo apurado em 1922, foi de 713:735\$400 (setecentos e treze contos setecentos e trinta e cinco mil e quatrocentos réis), havendo, portanto, uma differença a mais de 42:659\$000 (quareta e dois contos seiscentos e cincoenta e nove mil réis).

O Thesoureiro bem cumpriu os seus deveres.

Secretaria. - Os serviços da Secretaria desta Facul. dade estiveram sempre em dia, tendo os empregados bem cumprido os seus deveres.

Secretaria da Faculdade de Direito de São Paulo, em 24. de Janeiro de 1924.

O Director:

Dr. Uladislau Herculano de Freitas 